\title{
DIGITAL DIVIDE IN THE EU COUNTRIES FROM THE DANUBE REGION
}

\author{
Sorin Dan Şandor ${ }^{1}$
}

\begin{abstract}
The paper analyzes digital divide in the EU Countries belonging to the Danube Region. Based on data from Eurobarometer 84.2 October 2015, digital divide (both in terms of access and usage) is assessed and then discussed in the light of the evolutions of digital divide in the last ten years for the countries from the region as reflected by Eurostat data. The influence of the most important factors mentioned in the literature (age, education, gender, rural-urban split, socio-economic status) is analyzed for each country.
\end{abstract}

The results show us that digital divide, while declining, is still of concern in the area. We found that age is a common factor for digital divide in all the cases and education is not influencing the digital divide in any of the countries in discussion. For the other factors their influence varies from country to country.

\section{Introduction}

Digital divide might be defined in many ways, each suggesting a different approach in measuring it. The main components of possible definitions are:

- access to digital resources like the Internet (later being supplemented with the quality of accessbroadband or not);

- $\quad$ computer literacy (knowledge and skills to use computers and similar digital devices);

- usage (distinctions are made from the most simplistic as use/not use to more precise measurements of the level of sophistication in usage).

Computer literacy is starting to become less and less important. The technologies used for access are becoming simpler every day - if at the beginning of the global network in order to have access in-depth knowledge was required, now even toddlers might be able to access digital content over the Internet.

Usage or sophistication is another issue - the way in which information is dealt with is depending primarily on the needs and wishes of the user. Brandtzæg et al [1] identified five user types: NonUsers, Sporadic, Instrumental, Entertainment and Advanced Users, considering the first two categories as being affected by digital divide. Sophistication is measured as the number of different purposes for using the Internet. Things are not as simple - the results may be explained by users' choices - they might decide to use or not to use a specific tool or use only some of its features. Needs are one determinant of usage - if someone needs to access electronic public services than the sophistication of usage might increase, but otherwise it stay at a lower level. Computer literacy

\footnotetext{
${ }^{1}$ Babeş-Bolyai University, Cluj-Napoca
} 
might be another factor - more knowledge might bring more sophisticated usage, but not exactly in terms of more ways of using the Internet. A survey made in Netherlands showed that people with low level of education are using the Internet more than the rest of the population [5] and the difference in the type of usage is that the lower educated use the Internet more for gaming and social interaction and less for information and for personal development than the higher educated but they are still sophisticated enough - in the terms of Brandtzæg et al [1].

For the purpose of this paper, while acknowledging that digital divide is a complex phenomenon we will adopt an operational definition - digital divide is about access to Internet. We identified two groups: people who did never accessed the Internet (because of lack of connection or from other reasons) and people who did.

The factors that are influencing digital divide are many. Different sets of factors are mentioned, such: socioeconomic status, gender, life stage (age) and geographic location (affluence of the region) [2], or income, education, age, gender, ethnicity, and geographical location [10]. Tsatsou [9] is presenting a review of socio-cultural parameters that influence the decision to adopt digital technologies.

\section{Methodology}

The data used for our analysis was gathered through EUROBAROMETER 84.2, October 2015. We selected the data concerning EU countries from the Danube Region: Austria, Bulgaria, Croatia, the Czech Republic, Germany, Hungary, Romania, Slovakia and Slovenia.

Digital divide was measured using the answers to the question D62 from the questionnaire regarding the use of the Internet, values like „Never” or „No Internet access” are used to identify people which never accessed the Internet, the "digitally excluded".

The Eurobarometer gathers data for the main factors mentioned in the literature: age, geographic location (country and type of community), gender, education and income. Accordingly the hypotheses of the study are:

1. Age influences digital divide;

2. The type of community is influencing digital divide;

3. Gender influences digital divide;

4. Education is influencing digital divide;

5. Financial situation is influencing digital divide.

Binary logistic regressions were performed for each of the countries in order to identify the existence and the nature of stated relationships. Binary logistic regression estimates the probability that a characteristic is present (in this case digital exclusion) given the values of explanatory variables (age, type of community, gender, education and financial situation). The choice of this method is also influenced by the fact that variables are measured at different levels - age and education are measured at scale level, the type of community and the financial situation (measured as difficulty in paying the bills) at ordinal level and gender at nominal level. 


\section{Findings}

\subsection{Dimension of the digital divide}

The number of the digitally excluded (people which did not access the Internet) ranges between one fifth of the population over 15 years and almost one half, indicating a serious extent of the phenomenon. We can see that the richest countries are faring better (Germany and Austria), while poorer countries (Bulgaria and Romania) are the last. Other researches have different data for the number of people that never used the Internet. Eurostat is reporting, based on data from the surveys of the national statistics institutes a much lower figure. One possibility for the lower figure is that only people under 75 years are included in such statistics or people over 75 are in a great proportion digitally excluded. In our data people over 75 years are representing $8.1 \%$ of the entire sample, but $20.5 \%$ of the people that never accessed the Internet (more than half of them - 56.5\%). Also it is unclear if people with no access were reported as having never accessed the Internet - in Eurobarometer No Access and Never are two different values of the Internet access variable. Eurostat figures are, except some cases (Slovakia and Hungary or Romania and Bulgaria are switching places), confirming the ranks that countries have from the point of digital divide.

\begin{tabular}{|l|r|r|}
\hline \multicolumn{1}{|c|}{ Country } & Digital exclusion & $\begin{array}{c}\text { Individuals that never used the } \\
\text { Internet (Eurostat, 2016) }\end{array}$ \\
\hline DE - Germany & $20,3 \%$ & $8 \%$ \\
\hline AT - Austria & $28,8 \%$ & $13 \%$ \\
\hline CZ - Czech Republic & $30,3 \%$ & $13 \%$ \\
\hline SI - Slovenia & $30,3 \%$ & $22 \%$ \\
\hline HR - Croatia & $34,0 \%$ & $23 \%$ \\
\hline SK - Slovakia & $34,9 \%$ & $15 \%$ \\
\hline HU - Hungary & $36,3 \%$ & $19 \%$ \\
\hline BG - Bulgaria & $44,0 \%$ & $33 \%$ \\
\hline RO - Romania & $48,7 \%$ & $30 \%$ \\
\hline Total & $27,3 \%$ & - \\
\hline
\end{tabular}

Table 1: Dimension of the digital divide

Eurostat figures are helping us to see that the region is lagging behind the rest of the Europe. The average figure of EU-28 is 14\% - only three countries from the region are better than the average, Germany being only the seventh in the EU; Romania and Bulgaria are the last in the ranks.

Internet access is becoming less and less problematic. The percentage of people not having Internet at all ranges from $3.4 \%$ in Germany to $14.6 \%$ in Bulgaria. At European level most common mentioned reasons for households not having internet access are that it is not needed (46\%), they lack the skills (41\%) or the equipment (27\%) or access $(23 \%)$ costs are too high [4:6].

The digital gap at country level is smaller now than it was ten years ago. The biggest increase in terms of Internet users was in Romania, followed by Bulgaria and Croatia. EU-28 has a better rate than EU-15. In some areas the new EU member states have better indicators than older states. Romania leads in terms of ultrafast (at least 100MBps) broadband [4:19). The country with the biggest proportion of internet users on social networks is Hungary with $83 \%$, Romania (together with two other states) follows with $78 \%$ of users and Bulgaria is only two percent behind. (4:14). Still, the digital economies of the less developed countries in the EU are lagging behind, Bulgaria 
and Romania being the last. The Danube Region has only two countries with digital economies above EU-28 average - Germany and Austria. The economic factor is important. James [7] found that in the developing countries where incomes tend to be relatively high the divide is falling, which also is the case for the poorer member states of the EU.

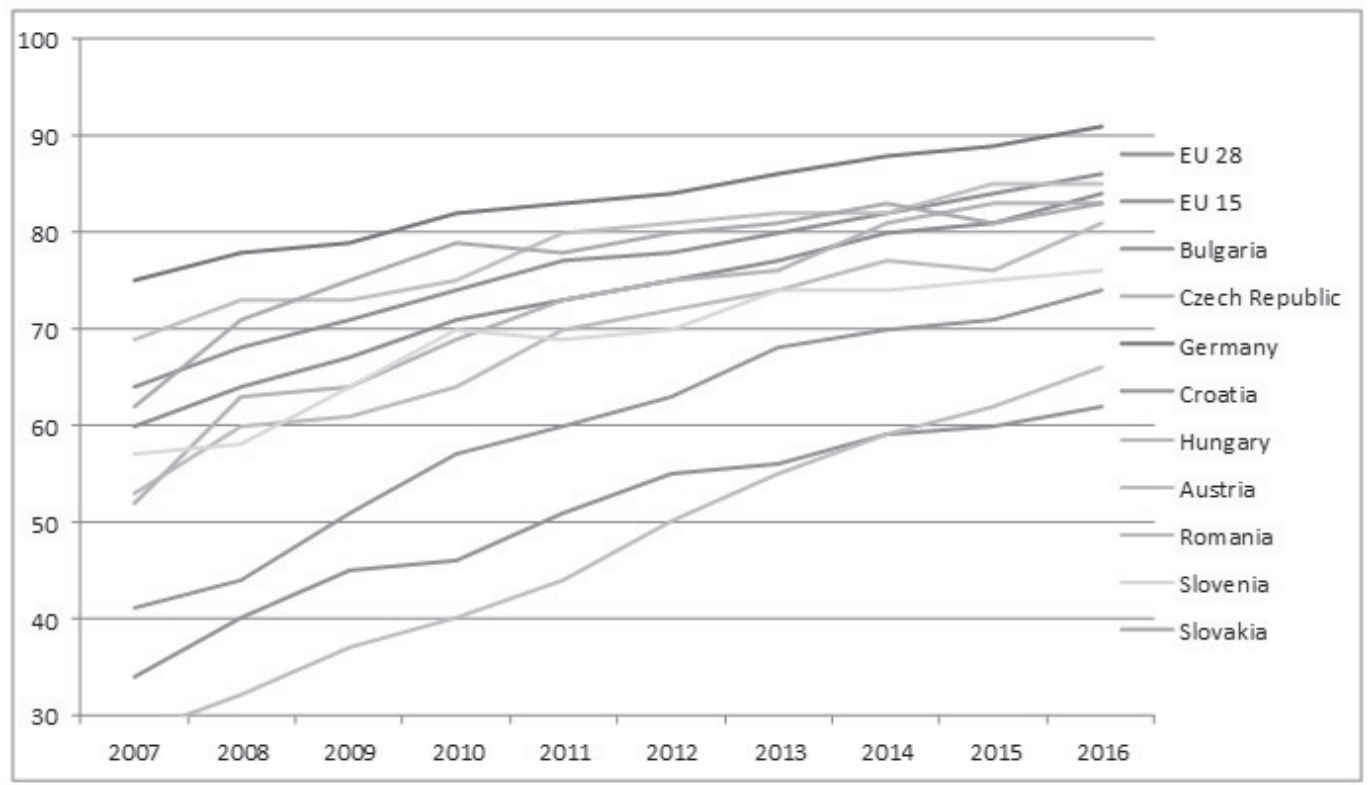

Figure 1: Evolution of the number of Internet users (source: Eurostat)

\subsection{Profile of digitally excluded}

How do people that have never accessed the Internet look like? Some characteristics are presented in the table below.

\begin{tabular}{|l|r|r|r|r|r|r|}
\hline \multicolumn{1}{|c|}{ Country } & \multicolumn{1}{c|}{$\begin{array}{c}\text { Age } \\
\text { (average) }\end{array}$} & $\begin{array}{c}\text { Gender } \\
(\% \text { of men) }\end{array}$ & $\begin{array}{c}\text { Rural } \\
(\%)\end{array}$ & $\begin{array}{c}\text { Small/middle } \\
\text { town }(\%)\end{array}$ & $\begin{array}{c}\text { Financial } \\
\text { difficulties } \\
(\%)\end{array}$ & $\begin{array}{c}\text { Education (\% that } \\
\text { left school before } \\
\text { 15 years })\end{array}$ \\
\hline AT - Austria & 66,11 & 48.7 & 34.9 & 35.4 & 5.8 & 44.7 \\
\hline BG - Bulgaria & 63,35 & 46.9 & 31.0 & 40.2 & 39.2 & 24.7 \\
\hline CZ - Czech Republic & 62,54 & 40.1 & 25.1 & 52.0 & 11.3 & 9.2 \\
\hline DE - Germany & 70,02 & 39.8 & 34.7 & 44.3 & 2.5 & 49.4 \\
\hline HR - Croatia & 62,20 & 42.1 & 51.0 & 26.9 & 18.4 & 27.3 \\
\hline HU - Hungary & 65,30 & 42.2 & 15.6 & 61.8 & 12.0 & 43.6 \\
\hline RO - Romania & 60,71 & 43.6 & 56.4 & 28.0 & 9.4 & 34.6 \\
\hline SI - Slovenia & 70,39 & 37.7 & 48.7 & 28.9 & 17.1 & 33.1 \\
\hline SK - Slovakia & 64,77 & 39.2 & 52.5 & 35.4 & 13.4 & 16.5 \\
\hline Total & 64,87 & 42.2 & 39.9 & 39.0 & 14.8 & 32.0 \\
\hline
\end{tabular}


This profile indicates a population which is old, mostly composed of women, living in rural or small cities areas, which have often financial difficulties (measured as having problems paying their bills). With the exception of the former Czechoslovaks, their education level is rather low. The variations among the countries are not far from expected (with the exception of the percentage of people reporting financial problems in Bulgaria).

\subsection{Determinants of digital divide}

Table 2 is suggesting that all five hypotheses might be confirmed.

A logistical regression for each of the countries was used in order to identify the existence and the nature of the relationships mentioned in the hypothesis.

The model has a good explanatory power as the values of Nagelkerke R-square are around 0.4-0.5 for all the regressions. The results are expressed in terms of odds (a value of 1.10 indicated that the chances of being digitally excluded are increasing 1.1 times than the rest of the population). Only significant values $(\mathrm{p}<0.05)$ are represented.

\begin{tabular}{|l|l|l|l|l|l|l|l|}
\hline & Age & $\begin{array}{l}\text { Gender } \\
\text { (Men) }\end{array}$ & Rural & $\begin{array}{l}\text { Small or } \\
\text { middle } \\
\text { sized city }\end{array}$ & Education & $\begin{array}{l}\text { Financial } \\
\text { situation }\end{array}$ & $\begin{array}{l}\text { Nagelkerke } \\
\text { R-square }\end{array}$ \\
\hline Austria & 1.15 & & 1.79 & 3.40 & & 2.73 & 0.473 \\
\hline Bulgaria & 1.18 & & 3.15 & 2.46 & & 3.47 & 0.491 \\
\hline Croatia & 1.16 & & & & & 3.25 & 0.522 \\
\hline $\begin{array}{l}\text { Czech } \\
\text { Republic }\end{array}$ & 1.12 & & & & & 2.16 & 0.506 \\
\hline Germany & 1.10 & 0.67 & & & & 2.09 & 0.526 \\
\hline Hungary & 1.12 & 1.63 & 2.62 & 2.33 & & & 0.448 \\
\hline Romania & 1.13 & & 3.88 & 2.11 & & 2.63 & 0.484 \\
\hline Slovakia & 1.13 & & & & & 9.29 & 0.437 \\
\hline Slovenia & 1.15 & & & & & 2.42 & 0.509 \\
\hline
\end{tabular}

Table 3: Factors affecting Digital Divide (odds)

Hypothesis 1 is confirmed for all the countries in the region - age is influencing the chances to be digitally excluded. There are very few cases of young people that do not have access or that never accessed the Internet. For older people chances to be included in this category are increasing, for persons over 75 the odds becoming higher than $50 \%$. The strength of the relationship is fairly similar in all countries (ranging from 1.10 to 1.18).

Hypothesis 2 is confirmed for four different countries: Austria, Hungary, Bulgaria and Romania. The high odds for Romania and Bulgaria are showing us that we will find very high occurrence of digital exclusion in the rural areas (in line with other data concerning the divide between rural and urban areas). Smaller figures are for small and middle sized cities. In Hungary the divide is smaller. Austria is presenting an interesting puzzle - the highest odds for digital exclusion are for people from small and medium sized cities.

Hypothesis 3 is confirmed only for two cases - Germany - where if you are a man decreases the odds and Hungary where we see an increase. We saw that the share of female digitally excluded is higher than their share in the general population. This is a common findings of such studies and led 
to the different attempts into explaining, like Cooper [3] suggesting that the digital divide is fundamentally a problem of computer anxiety whose roots are deep in socialization patterns of boys and girls. Van Dijk and Hacker [10] are showing that in the course of the 1990s the gender gap in the possession of ICTs has started to close. The results in this study may be closer to those obtained by Hilbert [6]. In a study concerning developing countries the relationship between gender and digital divide was proven to be a spurious one, employment, education and income being the reasons why gender and digital divide are correlated. In our case age might be one of the alternative explanations. We saw that older generations are more digitally excluded and we know that women are better represented among older generations so the higher proportion of women among digitally excluded might only represent their higher proportion among older population.

Hypothesis 4 is not confirmed for any of the countries in the region. A cross-tabulation between education and digital exclusion is showing significant but weak relationships for all the countries except Germany, Austria and the Czech Republic. In the logistic regression (where the influence of other factors is taken into consideration) the significance disappears. This is largely counterintuitive - as education is seen as a factor influencing social divides. In the case of digital use this explanation might not work. Using the Internet is simpler every day and there is no need for a lot of education in order to be able to do it. People with no formal education are more prone to be digitally excluded, but their number in the sample is too small in order to have a significant relationship. The relationship between Internet use and education is not as expected - the already mentioned study of Helsper and van Deursen [5] shows that people with low level of education are using the Internet more than the rest of the population.

Hypothesis 5 is confirmed for all the countries, except Hungary. People who often have difficulties in paying their bills (the proxy used for financial situation) are more likely to be digitally excluded. By taking another proxy - class, we see that the highest occurrence of digital exclusion appears for the working class $(53.1 \%$ of the entire sample), much higher than for the lower class $(28.4 \%)$. The problem is that class identification is highly subjective and it is influenced by age - older persons are more likely to identify themselves as belonging to the working class than the rest of the population.

Several of these factors are affecting digital divide in specific ways for each country. In order to provide further explanations more knowledge about the specificities of these countries is needed knowledge which the author of this paper does not possess. Why gender seems to influence digital divide in a certain way in Germany and in another one in Hungary is a question which needs more in-depth knowledge of those societies and other finding need similar knowledge.

\section{Conclusions}

Van Dijk and Hacker [10:321] identified four different positions regarding digital divide:

1. Denial of the existence of a digital divide.

2. Acceptance of some present divides, claiming that they will soon disappear.

3. Emphasis of digital divides that are supposed to grow and come on top of old inequalities based on income, education, age, gender, ethnicity, and geographical location.

4. Differentiation: some gaps are decreasing while others grow. 
The findings of this study are showing that we cannot deny the existence of the digital divide in the region - it is quite significant. The dimension of this divide is decreasing in a consistent way in the last 10 years. The countries at the bottom do have the more consistent increases in the rate of Internet users, but the gap is not closing in a fast enough pace and there are no prospects for closing the divide.

Only some old inequalities are influencing the digital divide. Across the entire region we see differences among countries, more affluent countries exhibiting a smaller digital divide.

Age is the only factor affecting in a consistent and similar way all the countries from the region. It affects mainly the older generations, younger ones being more digitally included. Sung [8] suggests that smartphone use reduces the digital divide across age, education level, occupation, and income levels. Today $43 \%$ of the Europeans (aged 16-74 years) use their mobile phone to access the internet $[4: 15]$.

Gender-based divide is a significant only in two cases (and in different ways). Comparing the rates in which the percentage of men and women which never used the Internet is decreasing we observe that in each country from the region the percentage of men is decreasing a little bit faster than in the case of women (Eurostat), the same happening across EU-28. This might be worrying - such a trend, if continued, may generate a new gender-based divide even in country where it is not significant. But if we do compare the rates in which digital divide is reducing based on gender and age we can see that women aged between 25 and 64 have better rates than men of the same age in all countries from the region except Slovenia - so the gender divide (if existing) is closing.

The type of community seems to add digital divide to already existing divides between big and small communities in another four countries - but rather existing divides are behind the existence of the digital divide across this line. The trend in the evolution of digital divide is in the favor of reducing this line of division - the advance in the number of Internet users in the last ten years (source Eurostat) is the biggest in sparsely populated areas (less than 100 inhabitants $/ \mathrm{km}^{2}$ ) then in intermediate urbanized areas (between 100 and 499 inhabitants $/ \mathrm{km}^{2}$ ), the smallest advance being in densely-populated areas (at least 500 inhabitants $/ \mathrm{km}^{2}$ ). Basically this supports a path-dependency explanation - new technologies arrive and are embraced in big cities, then spread to smaller cities and in the end arrive in villages. In the more developed countries such a phenomenon happened several years before, while in less developed countries from the region thing are happening in the last years - but at a very big speed (in Romania the number of Internet users from rural areas has increased 4.91 times in the last 10 years, in Bulgaria 2.3 times).

Regarding income the evolutions of digital divide in the last five years (Eurostat has data only for this period, and for Croatia only for the last two years) are indicating a reduction of the gap in terms of Internet use for people living in households with income in the first (the biggest increase) and second quartile.

There are only small indications of new digital divides. Some authors [5] claim that digital divides are shifting into differences of usage. The information rich are using the Internet less but better than the rest. But this is something that was true for any kind of media - books being only one example. 


\section{References}

[1] BRANDTZÆG, P.B., HEIMA, J. and KARAHASANOVIC, A.: Understanding the new digital divide - A typology of Internet users in Europe, in: International Journal of HumanComputer Studies, no. 69, 2011, pp. 123-138.

[2] CHEN, W. and WELLMAN, B.: The Global Digital Divide -Within and Between Countries, in: IT\&Society, 1:7, 2004, pp. 18-25.

[3] COOPER, J.: The digital divide: the special case of gender, in: Journal of Computer Assisted Learning, 22:5, 2006, pp. 320-334.

[4] EUROPEAN COMMISSION, Connectivity. Broadband market developments in the EU, Europe's Digital Progress Report 2016.

[5] HELSPER, E.J. and VAN DEURSEN, A.J.A.M.: Do the rich get digitally richer? Quantity and quality of support for digital engagement, in: Information, Communication \& Society, published online, 2016, pp. 1-15.

[6] HILBERT, M.: Digital gender divide or technologically empowered women in developing countries? A typical case of lies, damned lies, and statistics, Women's Studies International Forum, 34(6), 2011, pp. 479-489.

[7] JAMES J.: Are Changes in the Digital Divide Consistent with Global Equality or Inequality?, in: The Information Society: An International Journal, 27:2, 2011, 121-128.

[8] SUNG, W.: Digital Government and Wicked Problems: Solution and Problem, Information Polity, 21:3, 2016, pp. 291-306.

[9] TSATSOU, P.: Digital divides revisited: what is new about divides and their research?, in: Media, Culture\& Society 33:2, 2011, pp. : 317-331.

[10] VAN DIJK, J. and HACKER, K.: The Digital Divide as a Complex and Dynamic Phenomenon, in: The Information Society, 19:4, 2003, pp. 315-326. 